\title{
Reference evapotranspiration estimate with limited weather data across a range of Mediterranean climates
}

\author{
Mladen Todorovic $^{\mathrm{a}, *}$, Biljana Karic ${ }^{\mathrm{a}}$, Luis S. Pereira ${ }^{\mathrm{b}}$ \\ a International Centre for Advanced Mediterranean Agronomic Studies (CIHEAM), Mediterranean Agronomic Institute of Bari, Via Ceglie 9, 70010 Valenzano (BA), Italy \\ ${ }^{\mathrm{b}}$ CEER - Biosystems Engineering, Institute of Agronomy, Technical University of Lisbon, Portugal
}

\section{A R T I C L E I N F O}

\section{Article history:}

Received 8 March 2012

Received in revised form 10 December 2012

Accepted 21 December 2012

Available online 29 December 2012

This manuscript was handled by

Konstantine P. Georgakakos, Editor-in-Chief,

with the assistance of V. Lakshmi, Associate Editor

\section{Keywords:}

FAO Penman-Monteith temperature

method

Hargreaves-Samani equation

Reference evapotranspiration estimation

from temperature data

Data correction for aridity

Data correction for humidity

Spatial interpolation

\begin{abstract}
S U M M A R Y
The standard FAO Penman-Monteith (PM-ET ${ }_{0}$ ) method for computing the reference evapotranspiration $\left(\mathrm{ET}_{\mathrm{o}}\right)$, in addition to air temperature, needs data on solar radiation or sunshine duration, relative humidity and wind speed which are often lacking and/or do not respect appropriate quality requirements. Hence, in many cases, $\mathrm{ET}_{\mathrm{o}}$ has to be estimated with limited weather data using maximum and minimum temperature only. Essentially, two procedures are used when no more than temperature data are available: (i) the well-known Hargreaves-Samani equation (HS), or (ii) the PM-ET $\mathrm{P}_{0}$ method with weather parameters estimated from the limited available data, called PM temperature (PMT) method. The application of these temperature-based approaches often led to contradictory results for various climates and world regions. The data used in the analysis refer to 577 weather stations available through the CLIMWAT database. The results, confirmed by various statistical indicators, emphasized that: (a) in hyper-arid and arid zones, the performance of HS and PMT methods are similar, with root mean square errors (RMSEs) around $0.60-0.65 \mathrm{~mm} \mathrm{~d}^{-1}$; (b) in semi-arid to humid climates, the PMT method produced better results than HS, with RMSE smaller than $0.52 \mathrm{~mm} \mathrm{~d}^{-1}$; (c) the performance of PMT method could be improved when adopting the corrections for aridity/humidity in the estimation of the dew point temperature from minimum temperature data. The spatial elaboration of results indicated high variability of $\mathrm{ET}_{\mathrm{o}}$ estimates by different methods. Thus, a site-specific analysis using daily datasets of sufficient quality is needed for the validation and calibration of temperature methods for $\mathrm{ET}_{\mathrm{o}}$ estimate. Maps presenting indicative results on under/over estimation of $\mathrm{ET}_{\mathrm{o}}$ by both temperature methods may be useful for their more accurate application over different Mediterranean climates.
\end{abstract}

(C) 2012 Elsevier B.V. All rights reserved.

\section{Introduction}

Accurate estimation of reference evapotranspiration $\left(\mathrm{ET}_{\mathrm{o}}\right)$ is highly important in hydrological studies for the simulation of the soil water balance at different scales, water resources assessment and development of watershed management plans. Equally so, $\mathrm{ET}_{\mathrm{o}}$ plays a key role in the estimation of crop water requirements and irrigation scheduling, irrigation and drainage design, as well as in studies relative to climate variation and change. The Food and Agricultural Organization of United Nations (FAO) upgraded the methodologies for $\mathrm{ET}_{\mathrm{o}}$ estimation after assuming a new concept for reference crop evapotranspiration, which is described for the grass reference crop by the FAO Penman-Monteith (PM-ET $\left.{ }_{\mathrm{o}}\right)$ equation (Allen et al., 1998). This approach proved well for a variety of climates and time step calculations (Smith, 2000; Kashyap and Panda, 2001; Berengena and Gavilán, 2005; López-Urrea et al., 2006; Temesgen et al., 2005; Yoder et al., 2005; Allen et al.,

\footnotetext{
* Corresponding author. Tel.: +39 0804606235; fax: +39 0804606206.

E-mail address: mladen@iamb.it (M. Todorovic).
}

2006) and is currently adopted worldwide. The PM-ET o $_{\mathrm{o}}$ consists of a combination equation and, therefore, requires weather data on solar radiation $\left(R_{S}\right)$ or solar sunshine duration to estimate net radiation $\left(R_{n}\right)$, psycrometric or relative humidity variables used to estimate the vapour pressure deficit (VPD), wind speed $(U)$, and maximum and minimum temperature ( $T_{\max }$ and $T_{\min }$, respectively).

The computation of the PM-ET equation parameters should follow the procedures proposed by Allen et al. (1998). The use of alternative parameters' estimation procedures has been analysed by Nandagiri and Kovoor (2005), who have shown the need for strict adherence to recommended parameter computation procedures, especially for estimating the VPD and $R_{n}$ parameters. Gong et al. (2006) performed a sensitivity analysis of PM-ET $\mathrm{PT}_{0}$ relative to the climatic variables used and reported that wind speed is the variable with less impact on the accuracy of $\mathrm{ET}_{\mathrm{o}}$ estimates; contrarily, solar radiation and relative humidity are of major importance for an accurate PM-ET calculation. However, full weather datasets are lacking in many parts of the world and alternative approaches are then required for computing $\mathrm{ET}_{\mathrm{o}}$. When datasets 
are incomplete, the possible use of a weather data generator has been analysed by Stöckle et al. (2004) who clearly identified the need for at least 2 years of full daily datasets for appropriate calibration of the weather generator.

The guidelines for PM-ET ${ }_{0}$ computation (Allen et al., 1998) include two approaches when weather data are missing: (i) using an alternative equation such as the empirical Hargreaves-Samani (HS) equation (Hargreaves and Samani, 1985), or (ii) using alternative methods to estimate $R_{n}$, VPD and $U$ when calculating $\mathrm{ET}_{\mathrm{o}}$ with the same PM-ET $\mathrm{O}_{\mathrm{o}}$ method, hence, the minimum set of data required consists of $T_{\max }$ and $T_{\min }$. The latter approach, using a set of temperature data only, is called herein PM temperature (PMT) method and is often referred in literature as reduced set PM equation.

Several studies compared the $\mathrm{ET}_{\mathrm{o}}$ computed with the HS equa-

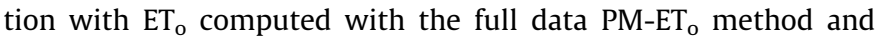
with grass lysimeter data. Results generally show a good performance of the HS equation except for humid climates, where it tends to overestimate $\mathrm{ET}_{\mathrm{o}}$ and where other equations, such as the Turc equation, can be preferred (Yoder et al., 2005; Nandagiri and Kovoor, 2006; Trajkovic and Kolakovic, 2009a; Martinez and Thepadia, 2010; Tabari, 2010). In fact, the HS method was developed using data from arid to sub-humid environments and, being an empirical equation, it does not fit well to conditions very different of those considered for its development as it is the case of humid climate. Other authors noticed that HS underestimates $\mathrm{ET}_{\mathrm{o}}$ for dry and windy locations because it does not have a wind term (e.g. Hargreaves and Allen, 2003; Temesgen et al., 2005; Berengena and Gavilán, 2005). Thus, despite the HS equation performs well for many applications, mainly when used for irrigation scheduling purposes, several researchers tried to calibrate the various parameters of the equation. Droogers and Allen (2002) explored recalibration of HS coefficients but did not improve HS estimates substantially. Further, other calibration attempts were performed and resulted in a number of HS equations depending upon the adopted parameters calibration (e.g., Gavilàn et al., 2005; Trajkovic, 2007; Fooladmand et al., 2008). Also, new models were developed such as a reference evapotranspiration model for complex terrains (REMCTs) developed from the HS equation and related recalibrated equations (Diodato and Bellocchi, 2007). Trajkovic (2005) reported that a radial basis function neural network predicted better PM-ET than locally calibrated temperature-based methods. Other authors also preferred the computation of $\mathrm{ET}_{\mathrm{o}}$ with limited data using neural networks, e.g., Khoob (2008) for semi-arid environments of Iran.

Hargreaves and Allen (2003) analysed carefully the HS equation, its history and applications, and concluded that attempts to recalibrate exponents and coefficients such as did by Allen (1993) and Droogers and Allen (2002) were not successful but increased the complexity of the HS equation. Temesgen et al. (2005) referred that the accuracy of HS is higher when 5 or 7-day $\mathrm{ET}_{\mathrm{o}}$ averages are adopted instead of daily values. Hargreaves and Allen (2003) called attention to the great advantage of HS equation relative to the combination equation, which is often overlooked, that is the reduced data requirement since only maximum and minimum air temperatures are required. This is important in regions where solar radiation, air humidity, and wind speed data are lacking or are of low or questionable quality. In fact, air temperature can be measured with less error and by less trained individuals than the other climate variables required by combination equations. Using recalibrated parameters reduces simplicity for users, even more if adopting neural networks procedures. However, Hargreaves and Allen (2003) admit that HS can be regionally or locally calibrated

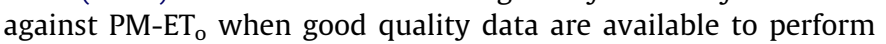
such a calibration. Following the discussions by Samani (2004), calibration may be useful for the solar radiation coefficient due to its large range of variation.
Several studies have assessed the accuracy of the PM-ET ${ }_{0}$ equation using only maximum and minimum temperature data (PMT)

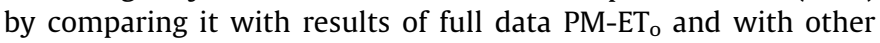
ET equations, mainly HS. An application to the North China Plain, under a monsoon climate, has shown that PMT daily estimates fit-

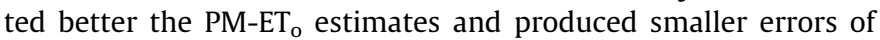
estimation than HS (Liu and Pereira, 2001; Pereira et al., 2003; Popova et al., 2006). Annandale et al. (2002) were successful in the application of PMT to various climates in South Africa, particularly when using 5-day averages of $\mathrm{ET}_{\mathrm{o}}$ rather than daily values. They found that the error in the calculated $\mathrm{ET}_{\mathrm{o}}$ due to prediction of missing weather data was generally in the range of the error induced by assuming a 95\% confidence interval in the measurements of $T_{\max }$ and $T_{\min }, \mathrm{RH}_{\max }$ and $\mathrm{RH}_{\text {min }}$, as well as $R_{\mathrm{s}}$ and $U$. Therefore, the error associated with the estimation of weather parameters was to some extent compensated for by the absence of measurements errors of the variables not observed (Annandale et al., 2002). This is true also for $\mathrm{ET}_{\mathrm{o}}$ estimates by any temperature method such as HS.

Trajkovic (2005) compared the PMT and HS with the full set $\mathrm{PM} \mathrm{ET}_{\mathrm{O}}$ in Serbia and found that PMT produced better results than HS, with RMSE between 0.16 and $0.52 \mathrm{~mm} \mathrm{~d}^{-1}$ and a regression slope relatively close to 1.0 . However, the author considered results not satisfactory despite errors are smaller than those reported in papers referred before relative to China $\left(0.7-0.8 \mathrm{~mm} \mathrm{~d}^{-1}\right)$ and to South Africa (0.42-0.60 $\mathrm{mm} \mathrm{d}^{-1}$ ). López-Moreno et al. (2009) reported that better results were obtained with PMT than with HS equation in Pyrenees. In a study relative to several humid locations and using various ET equations, Trajkovic and Kolakovic (2009b) found that HS ranked last but, unfortunately, PMT was not assessed. However, later, Gocic and Trajkovic (2010) proposed a Windows-based software to estimate $\mathrm{ET}_{\mathrm{o}}$ for minimizing computation errors when weather data are missing if using the PMT or an adjusted HS equation.

Popova et al. (2006) found that PMT provides more accurate results compared to the HS equation, which tended to overestimate $\mathrm{ET}_{\mathrm{o}}$ in the Trace plain area of south Bulgaria. Standard errors of estimate (SEE) for PMT ranged $0.52-0.69 \mathrm{~mm} \mathrm{~d}^{-1}$. Jabloun and Sahli (2008) reported similar results for various locations in North and Central Tunisia: HS equation overestimated $\mathrm{ET}_{\mathrm{o}}$ whereas the PMT method produced better estimates with RMSE ranging 0.41-0.80 $\mathrm{mm} \mathrm{d}^{-1}$. However, Martinez and Thepadia (2010) compared PMT with HS for a humid climate and found HS to produce smaller overestimation errors than PMT. The PMT equation showed greatest errors in coastal stations while the HS equation showed greatest errors at inland and island locations in Florida. Kra (2010) applied a modified PMT method in West Africa, and Paredes and Rodrigues (2010) adopted PMT to estimate $\mathrm{ET}_{\mathrm{o}}$ in Portugal for irrigation scheduling purposes, and generally found larger estimation errors in humid locations. Cai et al. (2009) present an application of the PMT approach using weather forecasted climatic data for irrigation scheduling purposes. Current literature data show to be controversial when comparing HS and PMT results.

Data quality assessment and data correction for non-reference weather sites, i.e., where aridity is dominant, were proposed by Allen et al. (1998) as a pre-condition for accuracy of PM-ET calcu-

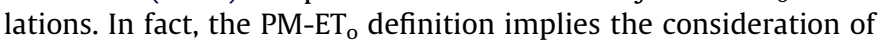
an actively growing grass crop completely shading the ground and not short of water. However, many, if not the majority of the weather data around globe is reported from non-reference sites, and their use to estimate $\mathrm{ET}_{\mathrm{o}}$ may cause less accuracy of estimates. Data quality is essential for any kind of evapotranspiration studies (Allen et al., 2011), and the requirements for aridity correction are particularly relevant for the PM-ET e $_{0}$ equation. That correction was analysed by Allen (1996), Jensen et al. (1997) and Temesgen et al. (1999), and refers to correct temperature by 2 or 3 degrees to approach $T_{\min }$ of $T_{\text {dew }}$ when the site temperature is higher than 
expected for a reference site while air humidity is lower. Temesgen et al. (1999) have shown small effects of this correction on $\mathrm{ET}_{\mathrm{o}}$ estimated with the HS equation because this equation does not explicitly use dew point temperature and wind speed, both of which are affected by site aridity. These authors also consider that the aridity of the site increases wind speed, which mixes up the top and bottom layers of the atmosphere. The mixing of different layers in turn reduces the temperature range $\left(\mathrm{TR}=T_{\max }-T_{\min }\right)$ by decreasing $T_{\max }$ during daytime and by increasing $T_{\min }$ during night-time, thereby keeping the increase in estimated $\mathrm{ET}_{\mathrm{o}}$ lower than with

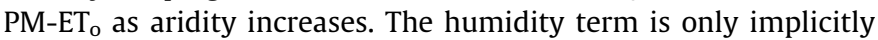
contained in the TR term of the Hargreaves equation. The analysis by Hargreaves and Allen (2003) agrees with the hypothesis of those authors, thus not considering the need for site aridity correction when the HS equation is used.

Several studies (Liu and Pereira, 2001; Annandale et al., 2002; Popova et al., 2006; Jabloun and Sahli, 2008; Paredes and Rodrigues, 2010) on using only temperature data to estimate $\mathrm{ET}_{\mathrm{o}}$ with the PMT method also report on the use of PM-ET ${ }_{0}$ when actual vapour pressure is computed with $T_{\min }$ to replace the dew point temperature $\left(T_{\mathrm{dew}}\right)$, when $R_{S}$ is estimated from the temperature range, and when wind speed is estimated by an average value, including a regional average as proposed by Allen et al. (1998) for conditions where the related variables are not available or observed with accuracy. That analysis is justified by the possible loss of accuracy due to parameters estimation, as referred by Allen (1997) and by the sensitivity study by Nandagiri and Kovoor (2005); nevertheless, these studies are relevant to assess the performance of $\mathrm{ET}_{\mathrm{o}}$ calculations when parameters related to a missing variable are replaced through an alternative calculation within the PM-ET $\mathrm{P}_{\mathrm{o}}$ equation. Results reported by studies quoted above show errors smaller than those obtained when only temperature data are used, i.e. when using the HS equation. However, those studies did not refer to site aridity correction on the estimation of VPD and $R_{s}$.

This work considers the need for a more accurate estimation of $\mathrm{ET}_{\mathrm{o}}$ to support a wide range of hydrological and irrigation management applications, particularly when weather data are missing or are of questionable quality. The study is focussed on a range of climates in the Mediterranean area with the objectives to assess: (1) the accuracy of the PMT and HS methods when compared with the

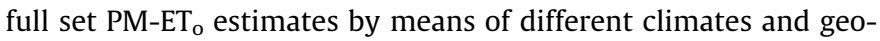
graphic (spatial) settings, (2) the effects on the performances of PMT method when adopting the corrections for site aridity/humidity on $T_{\mathrm{dew}}$ and VPD, $R_{n}$, and $\mathrm{ET}_{\mathrm{o}}$ estimates.

\section{Material and methods}

\subsection{Data}

The data used for this study were obtained from the United $\mathrm{Na}$ tions Food and Agriculture Organization (UN-FAO) database known as CLIMWAT (Smith, 1993). This database consists of climatic data from 3262 meteorological stations in 144 countries. The data include the long-term monthly average values for $T_{\max }, T_{\min }, R_{s}$, mean relative humidity $(\mathrm{RH})$, wind speed at $2 \mathrm{~m}\left(u_{2}\right)$ as well as total and effective precipitation, and $\mathrm{ET}_{\mathrm{o}}$ computed with the standard PM$\mathrm{ET}_{\mathrm{o}}$ equation. The CLIMWAT database has been used in several studies of evapotranspiration, e.g., those reported by Allen (1993, 1996, 1997), Temesgen et al. (1999), Droogers and Allen (2002), Valiantzas (2006) and Trajkovic and Kolakovic (2009a). Data used in this study refers to 16 Mediterranean countries (Algeria, Cyprus, Egypt, France, Greece, Italy, Jordan, Lebanon, Libya, Morocco, Portugal, Spain, Syria, Tunisia, Turkey and former Yugoslavia) and a total number of 570 weather stations. For a better representation of the area, data on seven weather stations of Portugal were added to the set.

All stations were grouped into six climate zones. These zones were defined according to the global aridity index (UNEP, 1997) adopted by the United-Nations Convention to Combat Desertification. The index consists of the ratio of mean annual precipitation $(P)$ to mean annual $\mathrm{ET}_{\mathrm{o}}$ as given in the CLIMWAT database. The distribution of weather stations into the various climate zones and into coastal or interior locations is given in Table 1 . The respective spatial distribution is presented in Fig. 1, which shows that humid and sub-humid climates dominate in northern Mediterranean regions, semiarid climates mostly occur in the vicinity of the Mediterranean sea, in Spain and in Turkey, while arid and hyper-arid climates dominate in the southern Mediterranean countries. This map also illustrates that the weather stations utilized in this study are quite well distributed through all considered countries.

\subsection{Methods used to estimate reference evapotranspiration}

The PM-ET ${ }_{0}$ equation was developed to describe ET of a reference grass crop, which is defined as the rate of evapotranspiration from a hypothetical crop with an assumed fixed height $(12 \mathrm{~cm})$, surface resistance $\left(70 \mathrm{~s} \mathrm{~m}^{-1}\right)$ and albedo $(0.23)$, closely resembling the evapotranspiration from an extensive surface of a disease-free green grass cover of uniform height, actively growing, completely shading the ground, and with adequate water and nutrient supply (Allen et al., 1998). The PM-ET ${ }_{o}$ equation for calculation of daily $\mathrm{ET}_{\mathrm{o}}$ takes the form:

$\mathrm{ET}_{\mathrm{o}}=\frac{0.408 \Delta\left(R_{n}-G\right)+\gamma \frac{900}{T+273} u_{2}\left(e_{s}-e_{a}\right)}{\Delta+\gamma\left(1+0.34 u_{2}\right)}$

where $\mathrm{ET}_{\mathrm{o}}$ is the grass reference evapotranspiration $\left[\mathrm{mm} \mathrm{day}^{-1}\right], R_{n}$ is the net radiation at the crop surface $\left[\mathrm{MJ} \mathrm{m}^{-2}\right.$ day $\left.^{-1}\right], G$ is soil heat flux density [MJ $\left.\mathrm{m}^{-2} \mathrm{day}^{-1}\right], T$ is mean daily air temperature at $2 \mathrm{~m}$ height $\left[{ }^{\circ} \mathrm{C}\right], u_{2}$ is wind speed at $2 \mathrm{~m}$ height $\left[\mathrm{m} \mathrm{s}^{-1}\right], e_{s}$ is saturation vapour pressure [kPa], $e_{a}$ is actual vapour pressure [ $[\mathrm{kPa}], e_{s}-e_{a}$ is saturation vapour pressure deficit [kPa], $\Delta$ is slope of the vapour pressure curve $\left[\mathrm{kPa}^{\circ} \mathrm{C}^{-1}\right]$, and $\gamma$ is psychometric constant $\left[\mathrm{kPa}{ }^{\circ} \mathrm{C}^{-1}\right]$. This equation uses standard meteorological records of solar radiation (net, short wave, or sunshine duration) or sunshine duration, minimum and maximum air temperature, air humidity (preferably minimum and maximum relative humidity) or wet and dry bulb temperature, and wind speed. To ensure the integrity of computations, the weather measurements should be made at $2 \mathrm{~m}$ (or converted to that height) above an extensive surface of green grass, shading the ground and not short of water. Standard methods are proposed by Allen et al. (1998) to compute the parameters of Eq. (1) from the observed climatic variables. In addition, alternative methods to estimate those parameters with missing climatic data are described below.

Net radiation $\left(R_{n}\right)$ is computed as the algebraic sum of the net short wave radiation $\left(R_{\mathrm{ns}}\right)$ and the net long wave radiation $\left(R_{\mathrm{nl}}\right)$ :

Table 1

Climate zones, respective precipitation to $\mathrm{ET}_{\mathrm{o}}$ ratios (adapted from UNEP, 1997) and number of stations in each zone.

\begin{tabular}{llccc}
\hline \multirow{2}{*}{ Climate zones } & Ratio $P / \mathrm{ET}_{\mathrm{o}}$ & \multicolumn{3}{c}{ Number of stations } \\
\cline { 3 - 5 } & & Total & Coastal & Interior \\
\hline Hyper-arid & $<0.05$ & 41 & 0 & 41 \\
Arid & $0.05-0.20$ & 57 & 16 & 41 \\
Semi-arid & $0.20-0.5$ & 175 & 36 & 139 \\
Dry sub-humid & $0.5-0.65$ & 103 & 34 & 69 \\
Moist sub-humid & $0.65-1.0$ & 117 & 46 & 71 \\
Humid & $>1.0$ & 84 & 24 & 60 \\
\hline
\end{tabular}




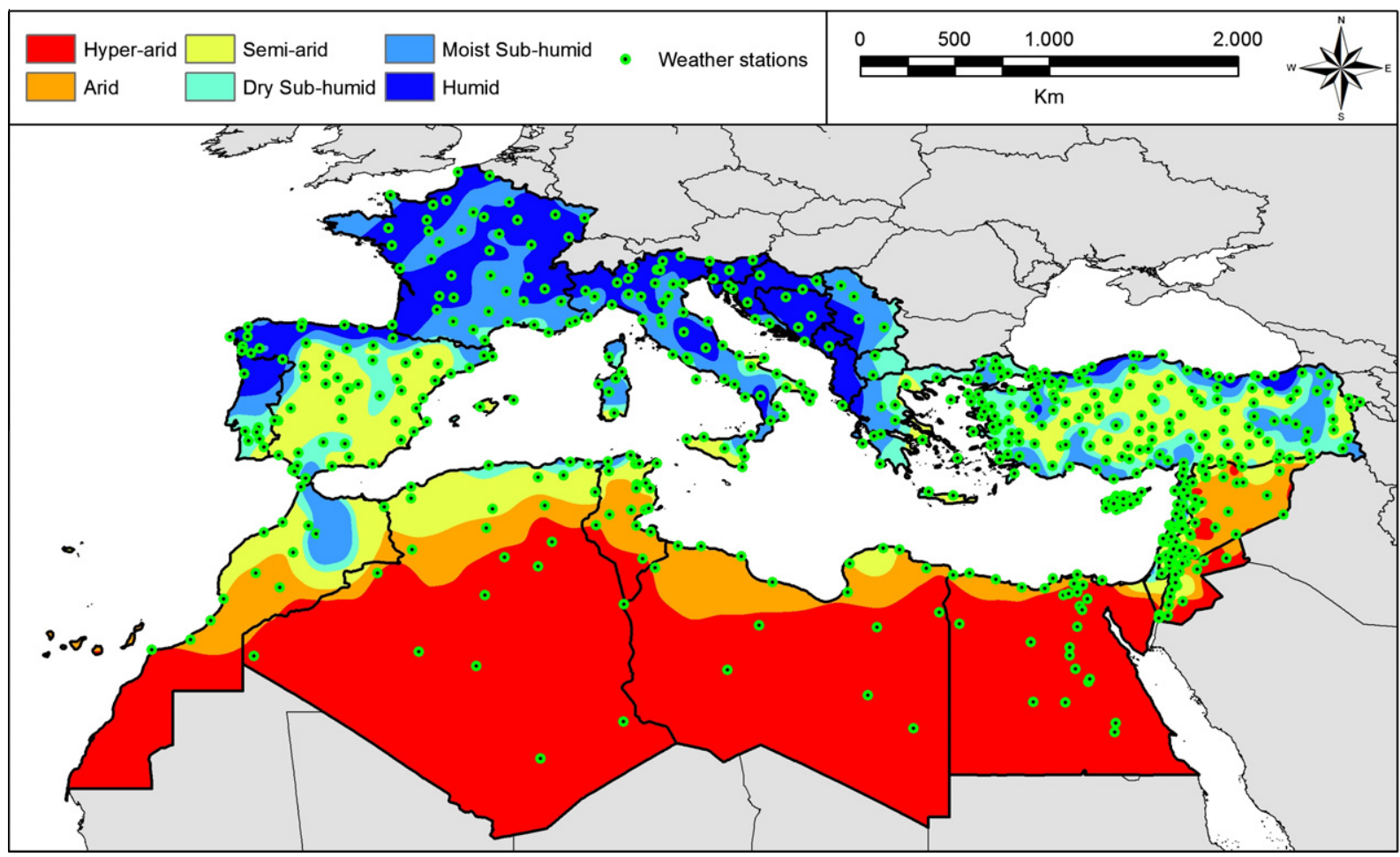

Fig. 1. Spatial distribution of climatic zones and weather stations utilized in this study.

$R_{n}=R_{\mathrm{ns}}+R_{\mathrm{nl}}$

Net short wave radiation $\left(R_{\mathrm{ns}}\right)$, resulting from the balance between incoming and reflected solar radiation, is given by

$R_{\mathrm{ns}}=(1-\alpha) R_{S}$

where $R_{\mathrm{ns}}$ is the net short wave radiation $\mathrm{MJ} \mathrm{m} \mathrm{m}^{-2} \mathrm{~d}^{-1}, \alpha$ is the albedo or canopy reflection coefficient [ ] fixed to 0.23 for the grass reference crop. When $R_{s}$ is not measured, it can be estimated from the observed duration of sunshine hours with the Angström (1924) equation:

$R=\left(a_{s}+b_{s} \frac{n}{N}\right) R_{a}$

where $R_{S}$ is solar or shortwave radiation $\left[\mathrm{MJ} \mathrm{m}^{-2}\right.$ day $^{-1}$ ], $n$ is actual duration of sunshine [h], $N$ is maximum possible duration of sunshine or daylight hours [h], $n / N$ is relative sunshine duration [-], $R_{a}$ is extraterrestrial radiation [ $\left[\mathrm{MJ} \mathrm{m}^{-2} \mathrm{day}^{-1}\right], a_{s}$ is the coefficient expressing the fraction of extraterrestrial radiation reaching the earth on overcast days $(n=0)$, and $a_{s}+b_{s}$ is the fraction of extraterrestrial radiation reaching the earth on clear sky days $(n=N)$. Extraterrestrial radiation $R_{a}$ and daylight hours $N$ are computed for any given day as a function of the latitude of the site (Allen et al., 1998). The values $a_{s}=0.25$ and $b_{s}=0.50$ are recommended when these fractions are not calibrated using a set of good quality data on both $n / N$ and $R_{s}$. However, these default values should not be applied to high elevation sites, where appropriate calibration is required (Ye et al., 2009).

When radiation and sunshine duration measurements are not available, the PMT method uses the Hargreaves radiation equation (Hargreaves and Samani, 1982) for the estimation of solar radiation $\left(R_{\mathrm{s}}\right)$ as:

$R_{s}=k_{\mathrm{Rs}} \sqrt{\left(T_{\max }-T_{\min }\right)} R_{a}$

where $k_{\mathrm{Rs}}$ is empirical radiation adjustment coefficient $\left[{ }^{\circ} \mathrm{C}^{-0.5}\right.$ ], which differs for 'interior' and 'coastal' regions. For 'interior' locations, where land mass dominates and air masses are not strongly influenced by a large water body, Allen (1995) suggested $k_{\mathrm{Rs}}=0.17\left(P / P_{o}\right)^{0.5}$; for 'coastal' regions it is proposed using $k_{\mathrm{Rs}}=0.20\left(P / P_{o}\right)^{0.5}$ to account for elevation effects on the volumetric heat capacity of the atmosphere, where $P$ and $P_{o}$ are mean atmospheric pressure of the site and at sea level, respectively [kPa]. However, later, Allen (1997) and Allen et al. (1998) proposed $k_{\mathrm{Rs}} \cong 0.16$ for 'interior' areas and $k_{\mathrm{Rs}} \cong 0.19$ for 'coastal' locations. These values are the same as those proposed previously by Hargreaves (1994). Thus, inherent to its empirical nature, there is some uncertainty relatively to this coefficient (Samani, 2004). The first version of Eq. (5) used $k_{\mathrm{Rs}} \cong 0.16$ but the value adopted later was $k_{\mathrm{Rs}} \cong 0.17$ (Samani, 2004). Popova et al. (2006) reported that both values produce very similar results. In the present study, both values (0.16 and 0.17$)$ were used for the interior locations whereas for the coastal stations $k_{\mathrm{Rs}}=0.19$ or 0.20 was applied.

Net long wave radiation $\left(R_{\mathrm{nl}}\right)$ resulting from the balance between the down-coming long wave radiation from the atmosphere $\left(R_{\mathrm{ld}} \downarrow\right)$ and the outgoing long wave radiation emitted by the vegetation and the soil $\left(R_{\mathrm{lu}} \uparrow\right)$ is:

$R_{\mathrm{nl}}=-f \varepsilon^{\prime} \sigma \frac{T_{\mathrm{Kx}}^{4}+T_{\mathrm{Kn}}^{4}}{2}$

where $R_{\mathrm{nl}}$ is the net long wave radiation [ $\mathrm{MJ} \mathrm{m}^{-2} \mathrm{~d}^{-1}$ ], $f$ is the cloudiness factor [ ], $\varepsilon^{\prime}$ is the net emissivity of the surface [ ], $\sigma$ is the Stefan-Boltzmann constant $=4.90 \times 10-9 \mathrm{MJ} \mathrm{m}^{-2} \mathrm{~K}^{-4} \mathrm{~d}^{-1}$, and $T_{\mathrm{Kx}}$ and $T_{\mathrm{Kn}}$ are respectively the maximum and minimum daily air temperature $[\mathrm{K}]$. The cloudiness factor $(f)$ represents the ratio between actual net long wave radiation and the net long wave radiation for a clear sky day and is:

$f=a_{c} \frac{R_{s}}{R_{\mathrm{so}}}+b_{c}$

where $R_{\text {so }}$ is the short wave solar radiation for a clear sky day $\left[\mathrm{MJ} \mathrm{m}^{-2} \mathrm{~d}^{-1}\right]$. The coefficients $a_{c} \approx 1.35$ and $b_{c} \approx-0.35$, with 
$a_{c}+b_{c} \approx 1.0$, are recommended for average climate conditions. $R_{\mathrm{so}}$ for daily periods can be estimated as:

$R_{s o}=\left(0.75+2 \times 10^{-5} z\right) R_{a}$

where $0.75=a_{s}+b_{s}$ (Eq. (4)), $z$ is the station elevation above sea level $[\mathrm{m}]$, and $R_{a}$ is the extraterrestrial radiation $\left[\mathrm{MJ} \mathrm{m} \mathrm{m}^{-2} \mathrm{~d}^{-1}\right]$. This equation is valid for $z<6000 \mathrm{~m}$ and low air turbidity.

The net emissivity of the surface $\left(\varepsilon^{\prime}\right)$ represents the difference between the emissivity by the vegetation and the soil and the effective emissivity of the atmosphere and is computed as:

$\varepsilon^{\prime}=0.34-0.14 \sqrt{e_{a}}$

where $e_{a}$ is the actual vapour pressure [kPa] defined below (Eq. (13)). The coefficients of Eq. (9) $\left(a_{1}=0.34\right.$ and $\left.b_{1}=-0.14\right)$ are recommended for average atmospheric conditions.

Vapour pressure deficit (VPD) is estimated as the difference between the saturation vapour pressure $\left(e_{s}\right)$ and the actual vapour pressure $\left(e_{a}\right)$

$V P D=e_{s}-e_{a}$

Saturation vapour pressure $\left(e_{s}\right)$ is computed as:

$e_{s}=\frac{e^{o}\left(T_{\max }\right)+e^{o}\left(T_{\min }\right)}{2}$

where $e^{o}(T)$ is the saturation vapour pressure function [kPa], and $T_{\max }$ and $T_{\min }$ are the maximum and minimum daily temperature $\left[{ }^{\circ} \mathrm{C}\right] . e^{o}(T)$ for air temperature $T$ is:

$e^{o}(T)=0.6108 \exp \left[\frac{17.27 T}{T+237.3}\right]$

When only mean daily relative humidity $\left(\mathrm{RH}_{\text {mean }}\right)$ data are available, as for the CLIMWAT database, the actual daily vapour pressure $e_{a}$ is computed as:

$e_{a}=\frac{R H_{\text {mean }}}{\frac{50}{e^{0}\left(T_{\min }\right)}+\frac{50}{e^{0}\left(T_{\max }\right)}}$

In the absence of humidity data, the actual vapour pressure, $e_{a}$, may be obtained by assuming that the dewpoint temperature, $T_{\mathrm{dew}}$, is close to the daily minimum temperature, $T_{\min }$, which is usually experienced at sunrise in reference weather stations. Then, if the weather station can be considered a reference site, $e_{a}$ is calculated by

$e_{a}=e^{o}\left(T_{\min }\right)=0.611 \exp \left[\frac{17.27 T_{\min }}{T_{\min }+237.3}\right]$

The HS method requires only minimum $\left(T_{\min }\right)$ and maximum $\left(T_{\max }\right)$ air temperature and extraterrestrial radiation $\left(R_{a}\right)$ for the estimation of $\mathrm{ET}_{\mathrm{o}}\left[\mathrm{mm} \mathrm{day}^{-1}\right]$ by the following equation:

$\mathrm{ET}_{\mathrm{o}}=0.0023 \frac{R_{a}}{\lambda} \sqrt{\left(T_{\max }-T_{\min }\right)}(T+17.8)$

The coefficient 0.0023 is an empirical coefficient including both the conversion from American to the International system of units and the $k_{\mathrm{Rs}}$ factor defined in Eq. (5) $\left(k_{\mathrm{Rs}} \cong 0.17\right.$ as described by Samani, 2004), $R_{a}$ is the extraterrestrial radiation as defined earlier, and $\lambda$ is the latent heat of vaporization $\left[\mathrm{MJ} \mathrm{kg}^{-1}\right.$ ] for the mean air temperature $T\left[{ }^{\circ} \mathrm{C}\right]$ given as:

$\lambda=2.501-0.002361 \cdot T$

Generally, it is assumed $\lambda=2.45 \mathrm{MJ} \mathrm{kg}^{-1}$.

\subsection{Adjustment of temperature when estimating reference evapotranspiration with the PMT method}

The PMT method uses as input only measured minimum and maximum air temperature for the estimation of $\mathrm{ET}_{0}$ by the $\mathrm{PM}$ $\mathrm{ET}_{\mathrm{o}}$ equation (Eq. (1)), whereas wind speed is fixed to $2 \mathrm{~m} \mathrm{~s}^{-1}$ (the average value of 2000 weather stations over the globe) and solar radiation and actual vapour pressure are estimated by Eqs. (5) and (14), respectively (Allen et al., 1998; Popova et al., 2006).

As discussed before, when applying the PMT method there is a need for adjustment of temperature used for the estimation of actual vapour pressure by Eq. (14). $T_{\min }$ might be greater than $T_{\mathrm{dew}}$ in a non-reference weather station, as for a station located inside a town or having dry or bare ground. Then, the estimated value for $T_{\text {dew }}$ from $T_{\text {min }}$ may require correction (Allen, 1996; Allen et al., 1998; Temesgen et al., 1999), which is expected to be higher in more arid climates. Considering the climate zones defined in Table 1 , the corrections of $T_{\mathrm{dew}}$ are proposed for all months where $P / \mathrm{ET}_{\mathrm{o}}<0.4$ as it is described in Table 2.

In humid climates, the performance of the PMT method might be compromised in a different way as referred by Trajkovic and Kolakovic (2009b) and Martinez and Thepadia (2010). If air humidity is high and temperatures are low, it is likely that $T_{\mathrm{dew}}>T_{\mathrm{min}}$. Then, considering the relations for $T_{\mathrm{dew}}$ in moist air proposed by Lawrence (2005), $T_{\text {dew }}$ was empirically approximated by

$T_{\text {dew }}=\left(\left(T_{\min }+T_{\max }\right) / 2\right)-a_{d}$

with $a_{d}=2{ }^{\circ} \mathrm{C}$ for the months when $0.8<P / \mathrm{ET}_{\mathrm{o}}<1.0$ and $a_{d}=1{ }^{\circ} \mathrm{C}$ if $P / \mathrm{ET}_{\mathrm{o}}>1.0$

\subsection{Spatial interpolation of data}

The spline interpolation technique with tension was applied for the spatial presentation of data over the whole Mediterranean region. The spline method estimates values using a mathematical function that minimizes overall surface curvature, resulting in a smooth surface that passes exactly through the input points (Jeffrey et al., 2001). This method has been applied in numerous studies at different scales referring to the spatial interpolation of climatological and hydrological variables (Apaydin et al., 2004; Tait and Woods, 2007; El Kenawy et al., 2010). In this work, the interpolation was done by considering only the data from 3 closest stations and attributing to them a minimum weight of 0.1 . The same technique was applied when analyzing the ratios of $\mathrm{ET}_{\mathrm{o}}$ estimate by HS and PMT and those obtained by PM-ET ${ }_{0}$ method.

\subsection{Evaluation procedure}

The PM-ET ${ }_{0}$ method consists of Eq. (1) with net radiation computed with the set of Eqs. (2), (3), (4), (6), (7), (8), and (9), and VPD computed with Eqs. (10)-(13). The HS method applies Eqs. (15) and (16) for the estimation of ET. The PMT method uses Eq. (1) with: (a) Eq. (5) replacing Eq. (4) for the estimation of $R_{s}$ from the temperature range, (b) Eq. (14) instead of Eq. (13) to compute $e_{a}$ from $T_{\min }$, and (c) wind speed $\left(u_{2}\right)$ fixed to $2 \mathrm{~m} \mathrm{~s}^{-1}$ for all locations.

Table 2

Correction of $T_{\text {dew }}$ estimates from $T_{\min }$ for estimation of actual vapour pressure.

\begin{tabular}{lll}
\hline Climate zones & Annual $P / \mathrm{ET}_{\mathrm{o}}$ & Corrected $T_{\mathrm{dew}}\left({ }^{\circ} \mathrm{C}\right)$ \\
\hline Hyper arid & $<0.05$ & $T_{\mathrm{dew}}=T_{\min }-4$ \\
Arid & $0.05-0.20$ & $T_{\mathrm{dew}}=T_{\min }-2$ \\
Semi-arid & $0.20-0.5$ & $T_{\mathrm{dew}}=T_{\min }-1$ \\
Dry sub-humid & $0.5-0.65$ & $T_{\mathrm{dew}}=T_{\min }-1$ \\
Moist sub-humid & $0.65-1.0$ & No correction for aridity \\
Humid & $>1.0$ & No correction for aridity \\
\hline
\end{tabular}


The results of $\mathrm{ET}_{\mathrm{o}}$ estimates obtained with limited (temperature) weather data (PMT and HS methods) were compared with those of the PM-ET ${ }_{0}$ obtained with full data, which are taken as reference.

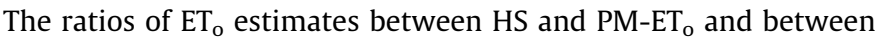

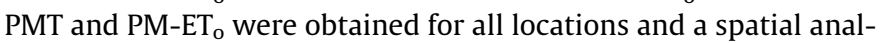
ysis was performed to identify where those temperature methods

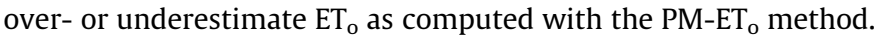
The statistical indicators described below (Eqs. (18)-(23)) were used to assess the performance of HS and PMT methods in respect to PM-ET ${ }_{0}$. All PMT computations were performed with and without correcting temperature for aridity effects (Table 2) and for humid locations (Eq. (17)). The datasets where a $T_{\min }$ correction was performed are labelled with the subscript "cor".

The analysis was performed grouping the results of $\mathrm{ET}_{0}$ estimate by climatic zones since several studies, mentioned previously, reported that both PMT and HS behave differently under different climates. Some authors also found differences in PMT and HS behaviour between coastal and interior locations; however, these differences were not consistent in the data set used in this study.

The goodness of fit was assessed through a set of indicators that are used to compare all pairs of observed and model-predicted values of the selected variables, $O_{i}$ and $P_{i}(i=1,2, \ldots, n)$, respectively, as well as the respective mean values $\bar{O}$ and $\bar{P}$. The indicators, well described for application by Popova and Pereira (2011), are the following:

- The coefficient of regression, $b$, and the coefficient of determination, $R^{2}$, of the linear regression forced to the origin relative to the $\mathrm{n}$ pairs of observed $\left(O_{i}\right)$ and predicted $\left(P_{i}\right)$ values $(i=1,2, \ldots, n)$ :

$$
\begin{aligned}
& b=\frac{\sum_{i=1}^{n} O_{i} \cdot P_{i}}{\sum_{i=1}^{n} O_{i}^{2}} \\
& R^{2}=\left\{\frac{\sum_{i=1}^{n}\left(O_{i}-\bar{O}\right) \cdot\left(P_{i}-\bar{P}\right)}{\left[\sum_{i=1}^{n}\left(O_{i}-\bar{O}\right)^{2}\right]^{0.5} \cdot\left[\sum_{i=1}^{n}\left(P_{i}-\bar{P}\right)^{2}\right]^{0.5}}\right\}^{2}
\end{aligned}
$$

where $\bar{O}$ and $\bar{P}$ are the mean values $O_{i}$ and $P_{i}$. If b is close to 1 then the predicted values are statistically close to the observed ones; when $R^{2}$ is close to 1.0 most of the variation of the observed values is explained by the model.

- The root mean square error, RMSE, expressed in the same units as $O_{i}$, which characterize the variance of the errors. Thus, the smaller RMSE indicates the better model's performance. RMSE is given as:

$$
R M S E=\left[\frac{\sum_{i=1}^{n}\left(P_{i}-O_{i}\right)^{2}}{n}\right]^{0.5}
$$

- The maximum absolute error, $E_{\max }$, again in the same units as $O_{i}$ :

$$
E_{\max }=\operatorname{Max}\left|P_{i}-O_{i}\right|_{i=1}^{n}
$$

- The modelling efficiency, EF, (non dimensional), that is a normalized statistic that determines the relative magnitude of the residual variance compared to the measured data variance (Nash and Sutcliffe, 1970; Moriasi et al., 2007). EF is defined by :

$$
E F=1.0-\frac{\sum_{i=1}^{n}\left(O_{i}-P_{i}\right)^{2}}{\sum_{i=1}^{n}\left(O_{i}-\bar{O}\right)^{2}}
$$

EF indicates that when the square of the differences between the model simulations and the observations is as large as the variability in the observed data, then $\mathrm{EF}=0.0$ and the observed mean, $\bar{O}$, is as good a predictor as the model; negative values indicate that $\bar{O}$ is a better predictor than the model (Legates and McCabe, 1999; Moriasi et al., 2007).
- The Willmott (1981) index of agreement, $d_{\mathrm{IA}}$, (nondimensional), that represents the ratio between the mean square error and the "potential error", defined as the sum of the squared absolute values of the distances from the predicted values to the mean observed value and distances from the observed values to the mean observed value (Moriasi et al., 2007):

$$
d_{\mathrm{IA}}=1-\frac{\sum_{i=1}^{n}\left(O_{i}-P_{i}\right)^{2}}{\sum_{i=1}^{n}{ }^{2}\left(\left|P_{i}-\bar{O}\right|+\left|O_{i}-\bar{O}\right|\right)^{2}}
$$

$d_{\mathrm{IA}}$ varies between 0 and 1 ; a value of 1 indicates a perfect agreement between the measured and predicted values while 0 indicates no agreement at all (Legates and McCabe, 1999; Moriasi et al., 2007).

\section{Results}

\subsection{Spatial analysis}

The results of the spatial interpolation of $\mathrm{ET}_{\mathrm{o}}$ estimates by PM$\mathrm{ET}_{\mathrm{o}}$ method over the whole Mediterranean area are given in Fig. 2 on the basis of annual $\mathrm{ET}_{\mathrm{o}}$ values. The spatial distribution of annual $\mathrm{ET}_{\mathrm{o}}$ follows closely the climatic zones distribution presented in Fig. 1, with lower $\mathrm{ET}_{\mathrm{o}}$ values for humid and sub-humid climates in northern Mediterranean regions and larger $\mathrm{ET}_{\mathrm{o}}$ estimates for arid and hyper-arid climates in the southern countries. The spatial variability of $\mathrm{ET}_{\mathrm{o}}$ is higher in the vicinity of the Mediterranean sea, where also semiarid climates mostly occur.

The range of annual $\mathrm{ET}_{\mathrm{o}}$ values varies from $576 \mathrm{~mm}$ at Lille (France), where climate is humid temperate, to $2539 \mathrm{~mm}$ at Aqaba Airport (Jordan), where climate is hyper-arid. $\mathrm{ET}_{\mathrm{o}}$ values below $600 \mathrm{~mm}$ were mainly observed in humid areas of France (e.g., Brest, Boulogne-Sur-Mer, Rouen, Nancy) and Italy (e.g., Tarvisio and Dobiaco). Areas having $\mathrm{ET}_{\mathrm{o}}<750 \mathrm{~mm}$ are located in northern France, northern Italy, Slovenia, northern Croatia, northern Bosnia and Herzegovina, eastern Serbia, and in mountain locations of eastern Turkey and northern Spain. $\mathrm{ET}_{\mathrm{o}}$ ranging from 750 to $1000 \mathrm{~mm}$ were estimated for northern Portugal, north-central Spain, central Italy, the Balkan peninsula, northern Greece and northern Turkey. Most of coastal and near-coastal areas of the Mediterranean have annual $\mathrm{ET}_{\mathrm{o}}$ between 1000 and $1500 \mathrm{~mm}$. Annual $\mathrm{ET}_{\mathrm{o}}>1500 \mathrm{~mm}$ are estimated for arid areas in Morocco, central and southern Algeria, Tunisia, Libya and Egypt, eastern Jordan and northeast Syria. $\mathrm{ET}_{\text {o }}$ above $2000 \mathrm{~mm}$ is detected in Libya (e.g., Sebha), Egypt (e.g., Aswan) and Algeria (e.g., Adrar). Locations having annual $\mathrm{ET}_{\mathrm{o}}$ above $2500 \mathrm{~mm}$ refer to desert areas in Algeria, Libya and Egypt.

Results of annual $\mathrm{ET}_{\mathrm{o}}$ estimates by HS and PMT were compared to the standard $\mathrm{PM}-\mathrm{ET}_{\mathrm{o}}$ method by means of the ratios $\mathrm{HS} /{\mathrm{PM}-\mathrm{ET}_{\mathrm{o}}}$ and PMT/PM-ET ${ }_{0}$ (or simply HS/PM and PMT/PM) for each of 577 locations. The spatial interpolation of HS/PM and PMT/PM over the whole Mediterranean area is presented in Figs. 3 and 4, respectively. The HS estimation of $\mathrm{ET}_{\mathrm{o}}$ is within $10 \%$ difference to ${\mathrm{PM}-\mathrm{ET}_{\mathrm{o}}}$ estimates, i.e., HS/PM ranged $0.9-1.1$ in most of hyper-arid and arid regions and large parts of semi-arid zones (cf. Fig.1). This range was observed for 252 stations (43\% of total). The PMT/PM ratio was within the range $0.9-1.1$ for 254 stations (43.1\%). For both HS and PMT, not only the referred number of stations but also their spatial distribution are quite similar when considering $10 \%$ differ-

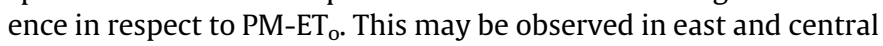
Spain, southern France and Italy, large areas of Turkey, central Syria and large areas of southern Mediterranean including Morocco, Algeria, Libya and Egypt. Comparing with Fig. 2, it may be observed that small over or under-estimation mostly occur when $\mathrm{ET}_{\mathrm{o}}$ is large or very large.

Underestimation of annual $\mathrm{ET}_{\mathrm{o}}$ by HS equation was observed in 250 locations (43\%) and underestimation by PMT was detected in 


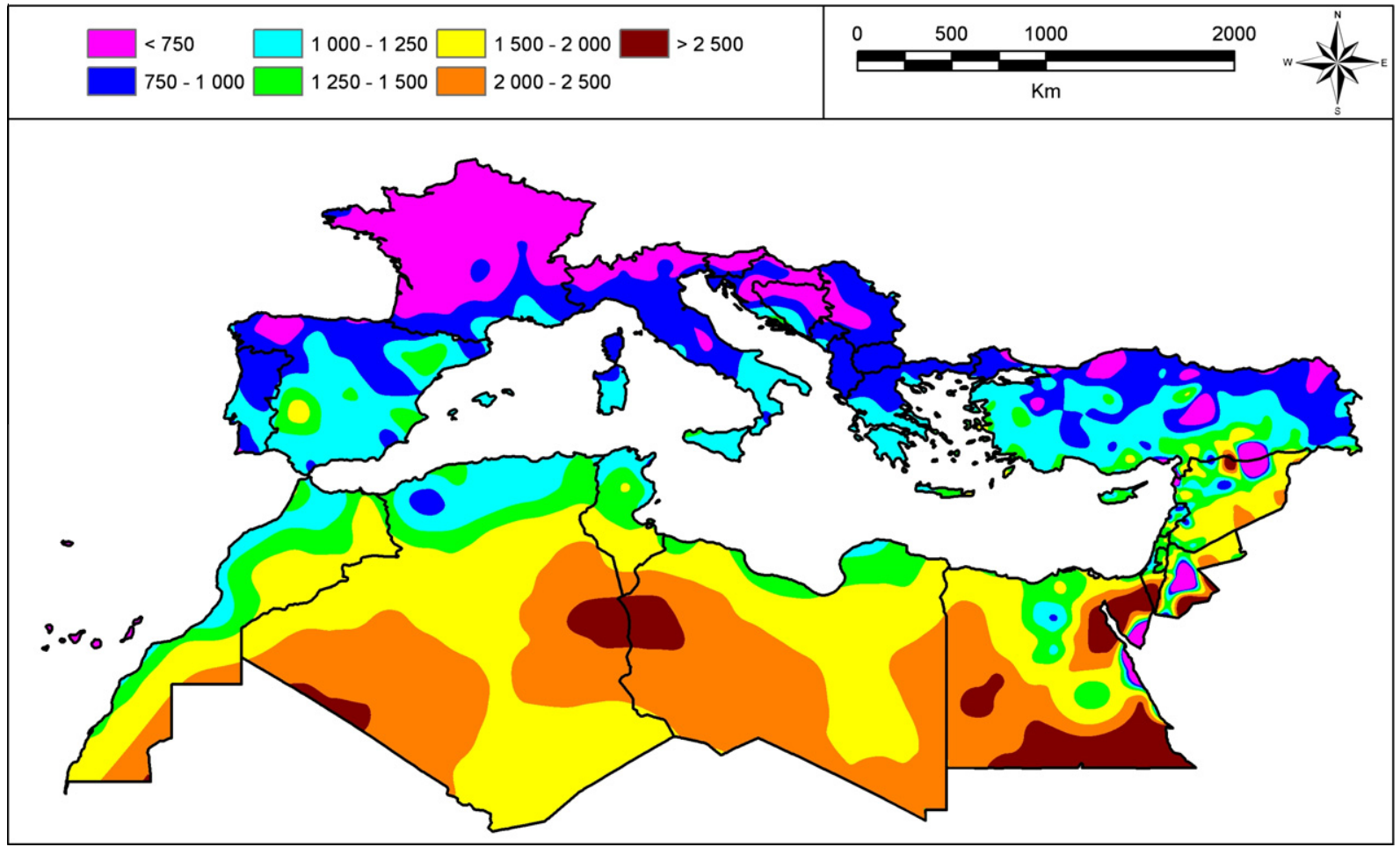

Fig. 2. Annual $\mathrm{ET}_{\mathrm{o}}$ over the Mediterranean countries estimated by PM-ETo method.

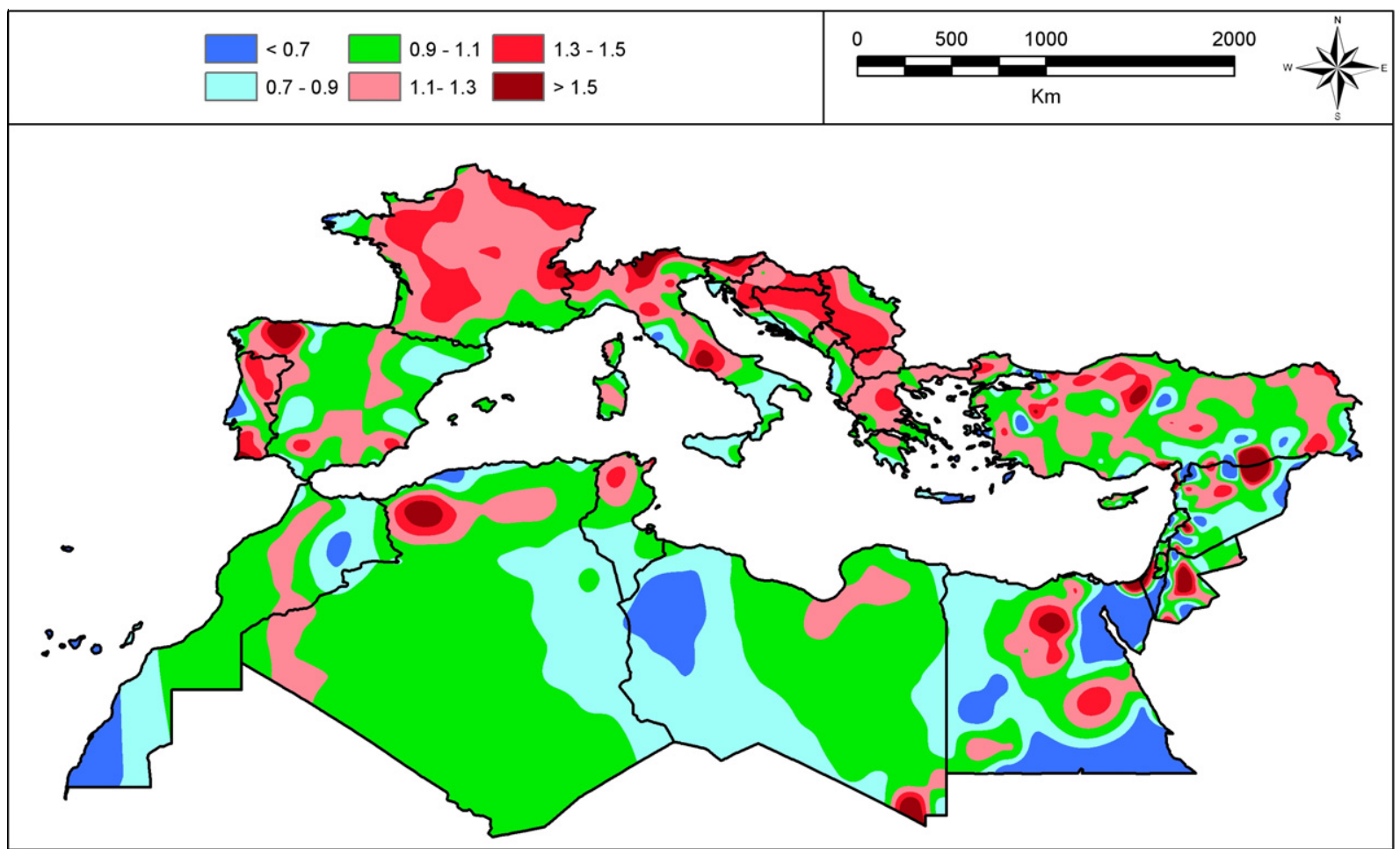

Fig. 3. Spatial distribution of the ratios of annual ETo estimates by HS to PM-ETo estimates over the Mediterranean region.

296 locations (or about 50.5\%). Most of stations with medium to high underestimation (greater than $10 \%$ ) are the same for both HS and PMT methods. Large underestimation occurs in coastal areas where, by effect of nearby large water masses, differences between maximum and minimum air temperature are often less than $10^{\circ} \mathrm{C}$, which leads to underestimation of net radiation and, to a less extend, also VPD. Sites with high underestimation of $\mathrm{ET}_{\mathrm{o}}$ include Greece (e.g., Naxos, Rodos and Hiraklion) and northern Egypt. Underestimation by HS also includes the locations where wind speed is high, e.g., Finisterre (Spain), where wind speed exceeds $5 \mathrm{~m} \mathrm{~s}^{-1}$. Underestimation greater than 10\% also occurs in arid areas of North Africa. For about $40.5 \%$ of locations, underestimation of 


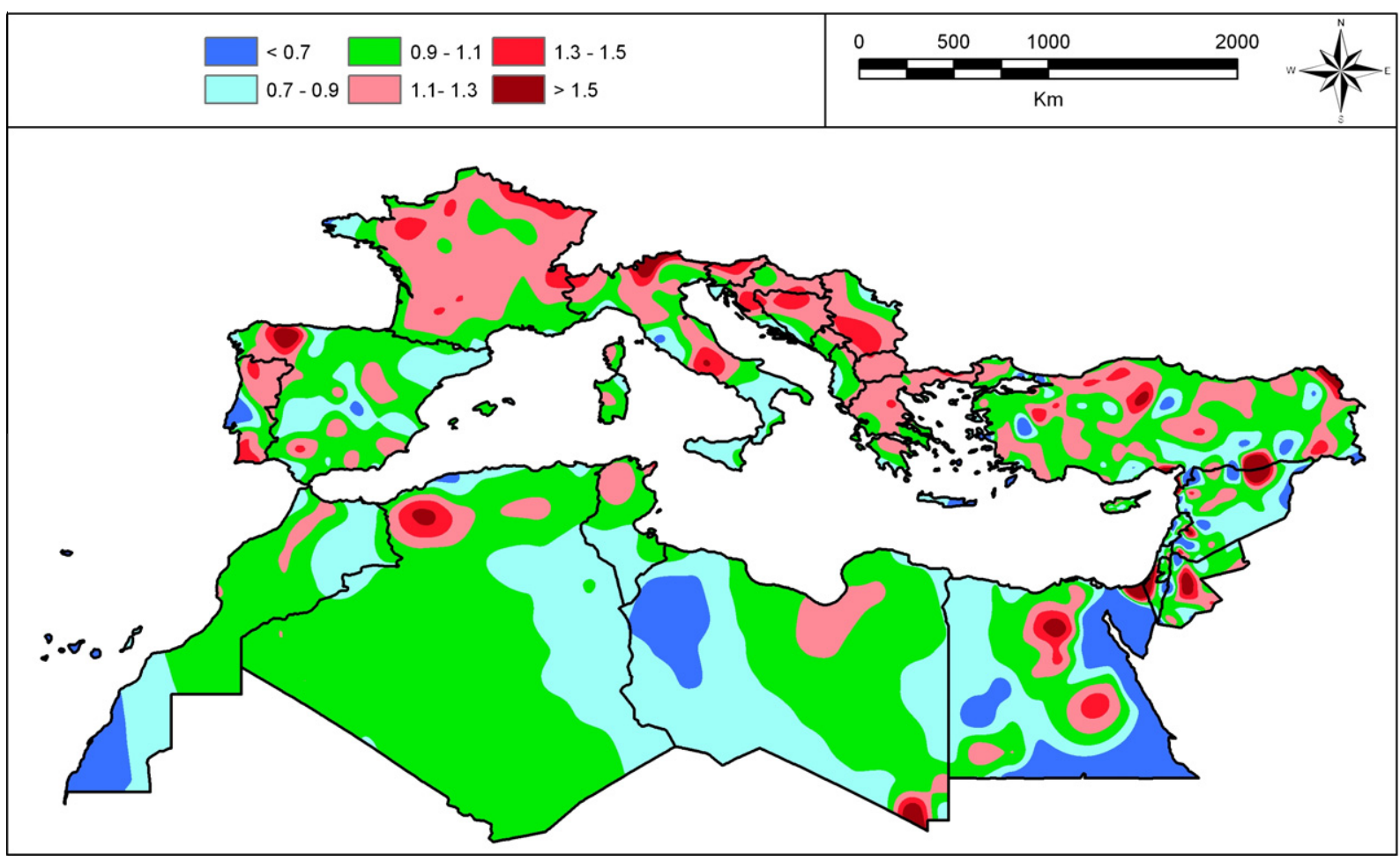

Fig. 4. Spatial distribution of the ratios of annual ETo estimates by PMT to PM-ETo estimates over the Mediterranean region.

annual $\mathrm{ET}_{\mathrm{o}}$ by PMT is smaller than $20 \%$, which denotes a more favourable behaviour than HS and likely relates to the fact that HS equation has not a wind term.

Overestimation of $\mathrm{ET}_{\mathrm{o}}$ by both HS and PMT methods was observed mainly in humid zones of northern Portugal, northern and central France and most of Balkan peninsula, northern and highland areas of Italy, and various locations in Turkey and southern Mediterranean. For most of those areas (40\% of considered locations) overestimation was smaller than $20 \%$. The overestimation of $\mathrm{ET}_{\mathrm{o}}$ by the HS equation in humid areas of Balkans and France was already reported by Trajkovic (2007).

Results do not show an evident relationship between over or under-estimation and climates, nor in favour of HS or PMT. This fact is likely to relate with data characteristics, eventually relative to influence of site aridity in case of PMT applications since mapped results did not consider that correction for aridity. Thus, HS and PMT methods looked to behave very similarly, which justifies the need to assess the impacts of correcting the data sets for aridity (Table 2) or to improve the estimation of $T_{\mathrm{dew}}$ in case of humid climates as analysed in the following section.

\subsection{Statistical analysis of the performance of HS and PMT methods}

A statistical analysis was performed to evaluate results of application of HS and PMT, the latter also including corrections of $T_{\text {dew }}$ estimated from $T_{\min }$ (identified as $\mathrm{PMT}_{\text {cor }}$ ) as indicated in Table 2 and Eq. (17). The indicators defined by Eqs. (18)-(23) were averaged by climatic zones and the results are presented in Table 3.

Overall, the HS and PMT methods have similar performance in the terms of the selected indicators (Table 3 ) although, for all climates, the PMT approach has greater modelling efficiency (EF) and index of agreement $\left(d_{\mathrm{IA}}\right)$ in respect to HS. The average modelling efficiency EF had quite high average values, as well as the index of agreement $d_{\mathrm{IA}}$, thus indicating that the use of temperature methods for $\mathrm{ET}_{\mathrm{o}}$ estimation is worthwhile in the current practice when only limited data are available. The average estimation errors
Table 3

Statistical indicators averaged by climatic zones comparing the performance of the Hargreaves-Samani (HS) and FAO-PM temperature (PMT) with the FAO-PM equation computed with full monthly datasets.

\begin{tabular}{|c|c|c|c|c|c|c|}
\hline & $b$ & $R^{2}$ & $\operatorname{RMSE}\left(\mathrm{mm} \mathrm{d}^{-1}\right)$ & $E_{\max }\left(\mathrm{mm} \mathrm{d}^{-1}\right)$ & $\mathrm{EF}$ & $d_{\mathrm{IA}}$ \\
\hline \multicolumn{7}{|c|}{ Hyper-arid climate } \\
\hline HS & 0.97 & 0.98 & 0.65 & 1.13 & 0.87 & 0.97 \\
\hline PMT & 0.95 & 0.98 & 0.64 & 1.11 & 0.88 & 0.97 \\
\hline $\mathrm{PMT}_{\text {cor }}$ & 1.00 & 0.99 & 0.68 & 1.14 & 0.86 & 0.96 \\
\hline \multicolumn{7}{|c|}{ Arid climate } \\
\hline HS & 0.98 & 0.98 & 0.60 & 1.09 & 0.85 & 0.96 \\
\hline PMT & 0.96 & 0.98 & 0.59 & 1.09 & 0.87 & 0.96 \\
\hline $\mathrm{PMT}_{\text {cor }}$ & 1.00 & 0.98 & 0.59 & 1.06 & 0.87 & 0.97 \\
\hline \multicolumn{7}{|c|}{ Semi-arid climate } \\
\hline HS & 1.01 & 0.98 & 0.52 & 0.96 & 0.89 & 0.97 \\
\hline PMT & 0.98 & 0.99 & 0.48 & 0.89 & 0.91 & 0.97 \\
\hline $\mathrm{PMT}_{\text {cor }}$ & 0.99 & 0.99 & 0.47 & 0.85 & 0.92 & 0.98 \\
\hline \multicolumn{7}{|c|}{ Dry sub-humid climate } \\
\hline HS & 1.01 & 0.98 & 0.59 & 1.08 & 0.85 & 0.96 \\
\hline PMT & 0.98 & 0.98 & 0.52 & 0.95 & 0.88 & 0.97 \\
\hline $\mathrm{PMT}_{\text {cor }}$ & 0.99 & 0.98 & 0.49 & 0.87 & 0.90 & 0.97 \\
\hline \multicolumn{7}{|c|}{ Moist sub-humid climate } \\
\hline HS & 1.04 & 0.98 & 0.47 & 0.86 & 0.87 & 0.97 \\
\hline PMT & 1.00 & 0.99 & 0.41 & 0.71 & 0.90 & 0.97 \\
\hline $\mathrm{PMT}_{\text {cor }}$ & 0.98 & 0.98 & 0.44 & 0.76 & 0.88 & 0.97 \\
\hline \multicolumn{7}{|c|}{ Humid climate } \\
\hline HS & 1.15 & 0.99 & 0.55 & 0.96 & 0.77 & 0.96 \\
\hline PMT & 1.08 & 0.99 & 0.42 & 0.70 & 0.87 & 0.97 \\
\hline $\mathrm{PMT}_{\text {cor }}$ & 1.02 & 0.99 & 0.36 & 0.67 & 0.90 & 0.98 \\
\hline
\end{tabular}

$b$ - coefficient of regression, $R^{2}$ - coefficient of determination, RMSE - root mean square error, $E_{\max }-$ maximum absolute error, $\mathrm{EF}$ - modelling efficiency, $d_{\mathrm{IA}}-$ index of agreement.

and coefficients of regression and determination were not very different for both temperature methods but errors decrease when $\mathrm{PMT}_{\text {cor }}$ is considered. Similarly, the highest values of both EF and $d_{\mathrm{IA}}$ correspond to $\mathrm{PMT}_{\text {cor }}$, i.e., it is apparently of interest to correct 
$T_{\min }$ for arid sites when calculating $T_{\text {dew. }}$. However, it is possible to detect differences in the accuracy of the various methods. RMSE and $E_{\max }$ average values are acceptable for practical irrigation scheduling.

In hyper-arid climates, the performance of HS and PMT methods are similar although PMT shows a greater trend of underestimation of $\mathrm{ET}_{\mathrm{o}}$ in respect to HS. Adopting a correction for aridity, when estimating $T_{\mathrm{dew}}$ from $T_{\mathrm{min}}$, does not reduce the estimation errors but only improves the coefficients of regression and determination. For $\mathrm{PMT}_{\text {cor }} \mathrm{b}$ becomes equal to 1.0, thus eliminating the overall trend of underestimation, and $R^{2}$ slightly increases to 0.99. The average RMSE of $\mathrm{PMT}_{\text {cor }}$ did not decrease relative to PMT but the respective range slightly decreased; the same was observed for $E_{\max }$. Higher underestimations by HS and PMT were observed for locations with high average wind speed (e.g., Aqaba, Jordan, where the average annual wind speed was $3.9 \mathrm{~m} \mathrm{~s}^{-1}$ ); contrarily, larger overestimations were for Gemmeiza, Egypt, with average annual wind speed of $0.82 \mathrm{~m} \mathrm{~s}^{-1}$. The average EF was high for both HS and PMT methods, 0.87 and 0.88 respectively. The average value for $d_{\mathrm{IA}}$ was 0.97 for both methods. Both indicators did not improve when the correction for aridity was adopted $\left(\mathrm{PMT}_{\text {cor }}\right)$. This correction improved the PMT estimations when $T_{\max }-T_{\min }$ was very high but not when that difference was relatively small. This difference however depends not only upon station aridity but also on the quality of related data. This correction impacted the estimation of both net radiation and VPD, with both decreasing the estimation errors and the respective ranges. Results did not show any significant difference between HS and PMT, thus leading to conclude that for hyper-arid climates it may be preferable to estimate $\mathrm{ET}_{\mathrm{o}}$ when data are lacking using the $\mathrm{HS}$ equation since it is easier to use than PMT and does not require temperature data correction.

For arid climates, both HS and PMT show a similar behaviour, with PMT $_{\text {cor }}$ showing slightly improved results. The average slope $b$ is close to 1 as well as $R^{2}$. The average RMSE and $E_{\max }$ are smaller than for hyper-arid climates but the average values for EF and $d_{\mathrm{IA}}$ are similarly high. Slight improvements in $\mathrm{PMT}_{\text {cor }}$ estimations mainly correspond to smaller range of indicators values. Differences between interior and coastal stations were small (data not shown) but, differently from PMT, HS tended to underestimate in coastal locations and to overestimate in interior ones. Similar behaviour of HS equation was observed in Spain (Vandelinden et al., 2004; Gavilàn et al., 2005) explaining that the underestimation in coastal areas is enhanced by the high wind velocity which tends to reduce temperature difference even more by mixing the lower layers of the atmosphere. Moreover, the underestimation of $\mathrm{ET}_{\mathrm{o}}$ by HS may be explained because PMT uses higher $k_{\mathrm{Rs}}$ values in coastal areas than in interior ones, while a unique value is used in HS as referred earlier. Results indicate that, as for hyper-arid climates, it is likely more appropriate to use HS method due to easiness computation and not requiring temperature adjustments. Results have shown that the estimation of $R_{n}$ was improved for $\mathrm{PMT}_{\text {cor }}$ relative to PMT but a trend for overestimation was detected; errors in estimating VPD were relatively high. Possibly, improvements of both HS and PMT may be obtained when selecting more appropriate $k_{\mathrm{Rs}}$ values to each station following the ranges indicated by Samani (2004).

In semi-arid climates, average RMSE relative to PMT and $\mathrm{PMT}_{\text {cor }}$ $\left(0.48\right.$ and $0.47 \mathrm{~mm} \mathrm{~d}^{-1}$ ) are lower than HS by respectively $8 \%$ and $10 \%$. Average $E_{\max }$ are also smaller. The average slope $b$ and $R^{2}$ are close to 1.0 for HS, PMT and PMT cor $_{\text {. The modelling efficiency }}$ and index of agreement are high for every computation method. The impact of correcting temperature for months when station aridity is expected is now visible, with the coefficient of regression $\mathrm{b}$ becoming equal to 1.0 for $\mathrm{PMT}_{\text {cor }}$ and errors of estimate decreasing relative to PMT. The indices EF and $d_{\mathrm{IA}}$ are higher than for arid and hyper-arid climates and are also improved in case of $\mathrm{PMT}_{\text {cor }}$. These more favourable results for PMT and $\mathrm{PMT}_{\text {cor }}$ are probably due to less extreme weather values when compared with more arid climates, thus inducing less impacts of adopting a narrow range for $k_{\mathrm{Rs}}$ values in PMT (0.16-0.17 for inland locations and 0.19-0.20 for coastal stations) and less differences to the HS adopted $k_{\mathrm{Rs}}=0.17$. When using daily data of good quality it is possible to search best values for this parameter $k_{\mathrm{Rs}}$. Nevertheless, results indicate that adopting the PMT or, better, $\mathrm{PMT}_{\text {cor }}$ may lead to higher accuracy in $\mathrm{ET}_{\mathrm{o}}$ estimates than using $\mathrm{HS}$.

Results for dry sub-humid regions are very similar to those of semi-arid climates. In fact, the range of variation of weather variables were not very different for both climates. Average RMSE of

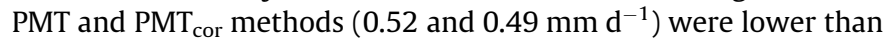
HS by $12 \%$ and $17 \%$ respectively. Average $E_{\max }$ were also smaller by $12 \%$ and $19 \%$. Hence, there is an evident superiority of PMT and $\mathrm{PMT}_{\text {cor }}$ methods relative to HS in terms of accuracy of estimates. There is also an evident impact of correcting temperature for months when station aridity was likely to occur. However, $b$ and $R^{2}$ were close to 1.0 for all methods. This indicates that over- and underestimates compensate each other when averaging values for all locations within the same climatic region. The modelling efficiency and index of agreement, EF and $d_{\mathrm{IA}}$, were high for all methods since their averages were close to 1.0.

In moist sub-humid areas, the regression slope $b$ was 1.04 for HS, thus indicating a trend for overestimation. Differently, the PMT method had $b=1.0$, i.e., without showing any trend to over or underestimation. Results of $\mathrm{PMT}_{\text {cor }}$ were inferior to those of PMT; corrections now refer to compensating $T_{\text {dew }}$ underestimation in wet months, and results have shown that such a correction was not required. The average RMSE $\left(0.47 \mathrm{~mm} \mathrm{~d}^{-1}\right)$ was $13 \%$ lower for PMT than for HS and the average $E_{\max }$ was also smaller by $17 \%$. The average EF was also better for PMT. This higher estimation accuracy by PMT leads to conclude that, as for dry sub-humid and semi-arid climates, adopting PMT is likely better than HS. Temperature corrections are not required for this climate condition.

In humid regions, the average regression coefficient was 1.15 for HS, 1.08 for PMT and 1.02 for $\mathrm{PMT}_{\text {cor }}$; corrections refer to compensating underestimation of $T_{\mathrm{dew}}$ in wet months (Eq. (17)). These results confirm those in literature for humid climates (e.g., Yoder et al., 2005; Nandagiri and Kovoor, 2006; Trajkovic and Kolakovic, 2009a; Martinez and Thepadia, 2010; Tabari, 2010): large overestimation by HS equation and high but smaller overestimation by PMT. Results for the average RMSE and $E_{\max }$ were coherent relative to the observed average b: estimate errors by PMT and PMT cor $_{\text {were }}$ $24 \%$ and $35 \%$ smaller than adopting the HS equation, and average $E_{\max }$ were respectively smaller by $27 \%$ and $30 \%$ than for HS. Coherently, results for EF show the average values 0.87 and 0.90 respectively for PMT and $\mathrm{PMT}_{\text {cor }}$ against the lower value of 0.77 relative to HS equation. Results indicate that HS is not appropriate for humid locations, that PMT provides better but less accurate estimates, and that correcting the estimate of $T_{\text {dew }}$ with Eq. (17) provides for good results. As revised before, several authors proposed the application of Turc equation for humid climates. Considering the results obtained with $\mathrm{PMT}_{\text {cor }}$ it is likely that there is no need to adopt a different equation. However, it is required to analyze the behaviour of the correction with Eq. (17) using daily datasets of recognized quality.

\section{Discussion}

In hyper-arid climates, $\mathrm{ET}_{\mathrm{o}}$ estimates by $\mathrm{HS}$ and PMT methods were similar and statistical indicators were also similar. Adopting PMT with a correction for aridity $\left(\mathrm{PMT}_{\mathrm{cor}}\right)$ did not reduce the estimation errors but slightly improved the goodness of fit indicators. 
Results did not show significant differences between HS and PMT, or between HS and $\mathrm{PMT}_{\text {cor. }}$ It clearly indicates that for hyper-arid climates the estimation of $\mathrm{ET}_{\mathrm{o}}$ with insufficient data may be advantageously performed using the HS equation since it is easier to use than PMT and does not require temperature data correction. For arid climates, both HS and PMT show also a similar behaviour. However, $\mathrm{PMT}_{\text {cor }}$ presented slightly better results relative to hyper-arid climates. Results indicate that, as for hyper-arid climates, it is likely more appropriate to use the HS method due to easy computation and no requirements of temperature adjustments. Possibly, improvements of both HS and PMT may be obtained when better selecting/calibrating $k_{\mathrm{Rs}}$ values, i.e., through improving the estimation of solar radiation.

Differently, in semi-arid and dry sub-humid climates the average RMSE and $E_{\max }$ relative to $\mathrm{ET}_{\mathrm{o}}$ estimates by PMT and $\mathrm{PMT}_{\text {cor }}$ are substantially lower than those for HS. However, the modelling efficiency $(\mathrm{EF})$ and the index of agreement $\left(d_{\mathrm{IA}}\right)$ were high for every computation method. The impact of correcting temperature for months when station aridity is expected was high, thus making it evident that temperature correction for aridity is greatly important in semi-arid and dry sub-humid climates. Hence, the use of PMT and $\mathrm{PMT}_{\text {cor }}$ are preferable relative to HS. Moreover, it is required that temperature data be corrected for aridity since this correction definitely improves results. This impact of correction for aridity is different of that for more arid climates because data for those climates presents more extreme values causing that small corrections may have less effects.

In moist sub-humid areas, HS has shown a trend for overestimation. Differently, the PMT did not show any trend to over or underestimation. In general, results did not show the need for temperature correction for aridity. Results for temperature correction to overcome the underestimation of $T_{\mathrm{dew}}$ in wet months also did not show any improvement. Thus, for moist sub-humid areas the best performance was observed for the PMT method without the need for temperature corrections.

In humid regions, it was observed a strong overestimation by HS, as already reported by many authors. An important but smaller overestimation was also observed for the PMT method. Differently, when the temperature was corrected to overcome the underestimation of $T_{\text {dew }}$ from $T_{\text {min }}$ in wet months (Eq. (17)), only a small overestimation was observed and the average RMSE and $\mathrm{E}_{\max }$ significantly decreased. Results for EF also show significantly higher average values than for the HS equation. It can be concluded that HS is not appropriate for humid locations, that PMT provides better but less accurate estimates, and that correcting the estimate of $T_{\text {dew }}$ with Eq. (17) produces better results. The results from $\mathrm{PMT}_{\text {cor }}$ somehow contradict those of various authors that proposed adopting the Turc equation for humid climates; in fact they did not test

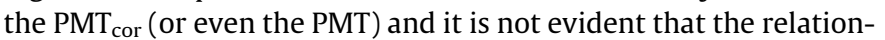

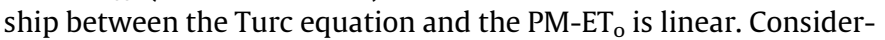
ing the results obtained with $\mathrm{PMT}_{\text {cor }}$ it is likely that there is no need to adopt a different equation; however, it is required to analyze the behaviour of the correction with Eq. (17) using daily datasets of recognized quality.

Despite the repeated advice in FAO56 and various papers in literature (Allen, 1996; Jensen et al., 1997; Allen et al., 1998; Temesgen et al., 1999), the fact is that most published results ignore the PMT method and the corrections for estimating $T_{\text {dew }}$ from $T_{\text {min }}$. Moreover, most of studies also do not discuss the impact of $k_{R s}$ on the performance of HS and PMT estimators. In reality that coefficient is not explicit in the Hargreaves equation (Eq. (15)) but is a part of the coefficient 0.0023. In case of PMT, it is explicit in Eq. (5) for computing $R_{s}$. Literature, with exception of the short article by Samani (2004), generally does not refer to the expected range of variation of $k_{\mathrm{Rs}}$; however, it may vary from 0.12 up to 0.24 . The possible adjustment of $k_{\mathrm{Rs}}$ concerns both HS and PMT, the latter relative to the $R_{S}$ estimation with Eq. (5). Relative to HS, it is preferably to write Eq. (15) differently, i.e., explicitly showing $k_{\mathrm{Rs}}$ :

$\mathrm{ET}_{\mathrm{o}}=0.0135 k_{\mathrm{Rs}} \frac{R_{a}}{\lambda} \sqrt{\left(T_{\max }-T_{\min }\right)}(T+17.8)$

where 0.0135 is the ratio between the coefficient 0.0023 to $k_{\mathrm{Rs}} \cong 0.17$, the value assumed in Eq. (15). It becomes therefore evident that a $k_{\mathrm{Rs}}$ may be searched with both Eqs. (5) and (24) to improve $\mathrm{ET}_{\mathrm{o}}$ estimates. In this study, $k_{\mathrm{Rs}}$ was 0.16 or 0.17 for interior locations and 0.19 or 0.20 for coastal locations; the smaller value was adopted when there was overestimation and the largest if PMT was underestimating. It is preferable to adjust $k_{\mathrm{Rs}}$ than to blindly change the coefficient 0.0023 , or the exponent of the temperature difference, thus altering the estimation of $R_{s}$, or changing the term $(T+17.8)$ using an exponent or changing the mean air temperature offset, thus the scaling of ET relative to the temperature difference. Searching the best $k_{\mathrm{Rs}}$ value with both Eqs. (24) and (5)(that is part of Eq. (24)) looks promising to avoid a multiplicity of HS equations as already are in literature.

\section{Conclusions}

Results of this study, covering a wide range of climates, from hyper-arid to humid, show that the performance of HS and PMT methods are different according to the climate under consideration and geographic (spatial) location of the sites of interest. Consequently, it is not possible to say that one method is superior to the other: where aridity dominates, the results for the HS equation are likely better than those for PMT, while results for PMT are better for less arid climates, from semi-arid to humid. These results somehow question the reason why PMT is often not considered by many authors in local and regional studies comparing the performance of various ET computational models against the PM-ET method. Results for the average modelling efficiency EF and the index of agreement $d_{\mathrm{IA}}$ computed for all climate zones are generally high, thus indicating that both HS and PMT approaches fit suffi-

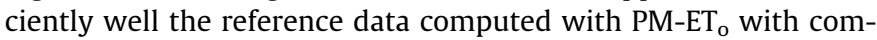
plete datasets. A few EF values may be low but they were always positive, thus supporting the appropriateness of model computations. However, the use of both temperature based methods for the estimation of $\mathrm{ET}_{\mathrm{o}}$ could be improved adjusting the empirical coefficient $k_{\mathrm{Rs}}$ for the estimation of solar radiation. Moreover, in the case of PMT, an ulterior progress could be achieved by adopting corrections for the estimation of $T_{\mathrm{dew}}$ from $T_{\text {min }}$. Finally, it is highly recommended to test and calibrate both temperature methods for ETo estimate against FAO PM-ETo method under different Mediterranean climates and geographic/orographic conditions but only when applied to good quality data sets.

\section{Acknowledgements}

This research has been done within the frame of: (1) WASSERMed project on "Water Availability and Security in Southern Europe and the Mediterranean", supported by the EC 7th Framework Programme (FP7-ENV) grant agreement $\mathrm{n}^{\circ} 244255$, and (2) Master of Science Programme in "Integrated land and water management: irrigated agriculture", organized by the International Centre for Advanced Mediterranean Agronomic Studies (CIHEAM) - Mediterranean Agronomic Institute of Bari.

\section{References}

Allen, R.G., 1993. Evaluation of a Temperature Difference Method for Computing Grass Reference Evapotranspiration. Report submitted to FAO, Rome.

Allen, R.G., 1995. Evaluation of Procedures for Estimating Mean Monthly Solar Radiation from Air Temperature. Report prepared for FAO, Rome. 
Allen, R.G., 1996. Assessing integrity of weather data for reference evapotranspiration estimation. J. Irrig. Drain. Eng. 122 (2), 97-106.

Allen, R.G., 1997. Self-calibrating method for estimating solar radiation from air temperature. J. Hydrol. Eng. 2 (2), 56-67.

Allen, R.G., Pereira, L.S., Raes, D., Smith, M., 1998. Crop Evapotranspiration. Guidelines for Computing Crop Water Requirements. FAO Irrig. Drain. Pap. 56, FAO, Rome, $300 \mathrm{p}$.

Allen, R.G., Pruitt, W.O., Wright, J.L., Howell, T.A., Ventura, F., Snyder, R., Itenfisu, D. Steduto, P., Berengena, J., Baselga, J., Smith, M., Pereira, L.S., Raes, D., Perrier, A., Alves, I., Walter, I., Elliott, R., 2006. A recommendation on standardized surface resistance for hourly calculation of reference ETo by the FAO56 PenmanMonteith method. Agric. Water Manage. 81, 1-22.

Allen, R.G., Pereira, L.S., Howell, T.A., Jensen, M.E., 2011. Evapotranspiration information reporting: I. Factors governing measurement accuracy. Agric. Water Manage. 98 (6), 899-920.

Angström, A., 1924. Solar and terrestrial radiation. Q. J. Roy. Meteor. Soc. 50, 121125.

Annandale, J.G., Jovanovic, N.Z., Benadé, N., Allen, R.G., 2002. Software for missing data error analysis of Penman-Monteith reference evapotranspiration. Irrig. Sci. $21,57-67$.

Apaydin, H., Sonmez, F.K., Yildirim, Y.E., 2004. Spatial interpolation techniques for climate data in the GAP region in Turkey. Climate Res. 28 (1), 31-40.

Berengena, J., Gavilán, P., 2005. Reference evapotranspiration estimation in a highly advective semiarid environment. J. Irrig. Drain. Eng. 131 (2), 147-163.

Cai, J., Liu, Y., Xu, D., Paredes, P., Pereira, L.S., 2009. Simulation of the soil water balance of wheat using daily weather forecast messages to estimate the reference evapotranspiration. Hydrol. Earth Syst. Sci. 13, 1045-1059.

Diodato, N., Bellocchi, G., 2007. Modeling reference evapotranspiration over complex terrains from minimum climatological data. Water Resour. Res. 43, W05444. http://dx.doi.org/10.1029/2006WR005405.

Droogers, P., Allen, R.G., 2002. Estimating reference evapotranspiration under inaccurate data conditions. Irrig. Drain. Syst. 16, 33-45

El Kenawy, A., Lopez-Moreno, J.I., Vicente-Serrano, S.M., Morsi, F., 2010. Climatological modeling of monthly air temperature and precipitation in Egypt through GIS techniques. Climate Res. 42 (2), 161-176.

Fooladmand, H.R., Zandilak, H., Ravanan, M.H., 2008. Comparison of different types of Hargreaves equation for estimating monthly evapotranspiration in the south of Iran. Arch. Agron. Soil Sci. 54 (3), 321-330.

Gavilàn, P., Lorite, I.J., Tornero, S., Berengena, J., 2005. Regional calibration of Hargreaves equation for estimating reference ET in a semi-arid environment. Agric. Water Manage. 81, 257-281.

Gocic, M., Trajkovic, S., 2010. Software for estimating reference evapotranspiration using limited weather data. Comp. Electr. Agric. 71, 158-162.

Gong, L., Xu, C.-Y., Chen, D., Halldin, S., Chen, Y.D., 2006. Sensitivity of the PenmanMonteith reference evapotranspiration to key climatic variables in the Changjiang (Yangtze River) basin. J. Hydrol. 329, 620-629.

Hargreaves, G.H., 1994. Defining and using reference evapotranspiration. J. Irrig. Drain. Eng. 120 (6), 1132-1139.

Hargreaves, G.H., Samani, Z.A., 1982. Estimating potential evapotranspiration. J. Irrig. Drain. Div. 108 (3), 225-230.

Hargreaves, G.H., Samani, Z.A., 1985. Reference crop evapotranspiration from temperature. Appl. Eng. Agric. 1 (2), 96-109.

Hargreaves, G.H., Allen, R.G., 2003. History and evaluation of Hargreaves evapotranspiration equation. J. Irrig. Drain. Eng. 129 (1), 53-63.

Jabloun, M., Sahli, A., 2008. Evaluation of FAO-56 methodology for estimating reference evapotranspiration using limited climatic data application to Tunisia. Agric. Water Manage. 95, 707-715.

Jeffrey, S.J., Carter, J.O., Moodie, K.B., Beswick, A.R., 2001. Using spatial interpolation to construct a comprehensive archive of Australian climate data. Environ. Model. Softw. 16 (4), 309-330.

Jensen, D.T., Hargreaves, G.H., Temesgen, B., Allen, R.G., 1997. Computation of ETo under nonideal conditions. J. Irrig. Drain. Eng. 123 (5), 394-400.

Kashyap, P.S., Panda, R.K., 2001. Evaluation of evapotranspiration estimation methods and development of crop-coefficients for potato crop in sub-humid region. Agric. Water Manage. 50, 9-25.

Khoob, A.R., 2008. Comparative study of Hargreaves's and artificial neural network's methodologies in estimating reference evapotranspiration in a semiarid environment. Irrig. Sci. 26, 253-259.

Kra, E.Y., 2010. An empirical simplification of the temperature Penman-Monteith model for the tropics. J. Agric. Sci. 2 (1), 162-171.

Lawrence, M.G., 2005. The relationship between relative humidity and the dewpoint temperature in moist air - a simple conversion and applications. Bull. Am. Meteorol. Soc. http://dx.doi.org/10.1175/BAMS-86-2-225.

Legates, D., McCabe, G., 1999. Evaluating the use of "goodness of fit" measures in hydrologic and hydroclimatic model validation. Water Resour. Res. 35 (1), 233 241.
Liu, Y., Pereira, L.S., 2001. Calculation methods for reference evapotranspiration with limited weather data (in Chinese). J. Hydraul. 3 (2001), 11-17.

López-Moreno, J.I., Hess, T.M., White, S.M., 2009. Estimation of reference evapotranspiration in a mountainous Mediterranean site using the PenmanMonteith equation with limited meteorological data. Pirineos 164, 7-31.

López-Urrea, R., de Santa, Martín., Olalla, F., Fabeiro, C., Moratalla, A., 2006. Testing evapotranspiration equations using lysimeter observations in a semiarid climate. Agric. Water Manage. 85, 15-26.

Martinez, C.J., Thepadia, M., 2010. Estimating reference evapotranspiration with minimum data in Florida. J. Irrig. Drain. Eng. 136 (7), 494-501.

Moriasi, D.N., Arnold, J.G., Van Liew, M.W., Bingner, R.L., Harmel, R.D., Veith, T.L., 2007. Model evaluation guidelines for systematic quantification of accuracy in watershed simulations. Trans. ASABE 50 (3), 885-900.

Nandagiri, L., Kovoor, G.M., 2005. Sensitivity of the Food and Agriculture Organization Penman-Monteith evapotranspiration estimates to alternative procedures for estimation of parameters. J. Irrig. Drain. Eng 131 (3), 238-248.

Nandagiri, L., Kovoor, G.M., 2006. Performance evaluation of reference evapotranspiration equations across a range of Indian climates. J. Irrig. Drain. Eng. 132 (3), 238-249.

Nash, J.E., Sutcliffe, J.V., 1970. River flow forecasting through conceptual models: Part 1 - a discussion of principles. J. Hydrol. 10 (3), 282-290.

Paredes, P., Rodrigues, G.C., 2010. Necessidades de água para a rega de milho em Portugal Continental considerando condições de seca. In: Pereira, L.S., Mexia, J.T., Pires, C.A.L. (Eds), Gestão do Risco em Secas. Métodos, Tecnologias e Desafios. Edições Colibri e CEER, Lisboa, pp. 301-320.

Pereira, L.S., Cai, L.G., Hann, M.J., 2003. Farm water and soil management for improved water use in the North China Plain. Irrig. Drain. 52 (4), 299-317.

Popova, Z., Kercheva, M., Pereira, L.S., 2006. Validation of the FAO methodology for computing ETo with missing climatic data. Appl. South Bulgaria Irrig. Drain. 55 (2), 201-215.

Popova, Z., Pereira, L.S., 2011. Modelling for maize irrigation scheduling using long term experimental data from Plovdiv region, Bulgaria. Agric, Water Manage. 98, 675-683.

Samani, Z., 2004. Discussion of "History and evaluation of Hargreaves evapotranspiration equation" by George H. Hargreaves and Richard G. Allen. J. Irrig. Drain. Eng. 130 (5), 447-448.

Smith, M., 1993. CLIMWAT for CROPWAT: A climatic database for irrigation planning and management. FAO Irrigation and Drainage Paper No. 49, Rome. (CLIMWAT 2.0) <http://www.fao.org/nr/water/infores_databases_climwat.html> and/or <http://www.fao.org/landandwater/aglw/climwat.stm>.

Smith, M., 2000. The application of climatic data for planning and management of sustainable rainfed and irrigated crop production. Agric. For. Meteorol. 103, 99108.

Stöckle, C.O., Kjelgaard, J., Bellocci, G., 2004. Evaluation of estimated weather data for calculating Penman-Monteith reference crop evapotranspiration. Irrig. Sci. 23, 39-46.

Tabari, H., 2010. Evaluation of reference crop evapotranspiration equations in various climates. Water Resour. Manage. 24 (10), 2311-2337.

Tait, A., Woods, R., 2007. Spatial interpolation of daily potential evapotranspiration for New Zealand using a spline model. J. Hydrometeorol. 8 (3), 430-438.

Temesgen, B., Allen, R.G., Jensen, D.T., 1999. Adjusting temperature parameters to reflect well-watered conditions. J. Irrig. Drain. Eng. 125 (1), 26-33.

Temesgen, B., Eching, S., Davidoff, B., Frame, K., 2005. Comparison of some reference evapotranspiration equations for California. J. Irrig. Drain. Eng. 131 (1), 73-84.

Trajkovic, S., 2005. Temperature-based approaches for estimating reference evapotranspiration. J. Irrig. Drain. Eng. 131 (4), 316-323.

Trajkovic, S., 2007. Hargreaves versus Penman-Monteith under humid conditions. J. Irrig. Drain. Eng. 133 (1), 38-42.

Trajkovic, S., Kolakovic, S., 2009a. Wind-adjusted Turc for estimating reference evapotranspiration ta humid European locations. Hydrol. Res. 40 (1), 45-52.

Trajkovic, S., Kolakovic, S., 2009b. Evaluation of reference evapotranspiration equations under humid conditions. Water Resour. Manage. 23, 3057-3067.

UNEP, 1997. World Atlas of Desertification, second ed. United Nations Environment Programme, Arnold, London, $182 \mathrm{p}$.

Valiantzas, J.D., 2006. Simplified versions for the Penman evaporation equation using routine weather data. J. Hydrol. 331 (3-4), 690-702.

Vanderlinden, K., Giràldez, J.V., Van Mervenne, M., 2004. Assessing reference evapotranspiration by the Hargreaves method in Southern Spain. J. Irrig. Drain. Eng. 129 (1), 53-63.

Willmott, C.J., 1981. On the validation of models. Phys. Geogr. 2, 184-194.

Ye, J., Guo, A., Sun, G., 2009. Statistical analysis of reference rvapotranspiration on the Tibetan Plateau. J. Irrig. Drain. Eng. 135, 134-140.

Yoder, R.E., Odhiambo, L.O., Wright, W.C., 2005. Evaluation of methods for estimating daily reference crop evapotranspiration at a site in the humid southeast United States. Appl. Eng. Agric. 21 (2), 197-202. 